\title{
The effects of Metformin Use on Body Mass Index: A Prospective Study
}

\author{
Sanjeev Tiwari ${ }^{1}$, Aseem Bhattarai ${ }^{2}$, Ramesh Prasad Acharya ${ }^{1}$, Pratap Narayan Prasad ${ }^{1}$
}

BACKGROUND: Limited number of studies has compared metformin with other Oral Hypoglycemic agents (OHAs) for reducing BMI and few of the results are controversial. Perhaps, this is of clinical importance because the Nepalese population presents different dietary habits in comparison with the European population. The objective of this study was to study the comparative evaluation of metformin with other OHAs influence on Body Mass Index (BMI) in Nepalese patients with diagnosed type 2 Diabetes Mellitus (T2DM)).

METHODS: A prospective cross sectional database of patients treated at diabetic clinic, TUTH, was analysed. Patients $(\mathrm{N}=115)$ with type 2 Diabetes Mellitus and with complete BMI and HbAlc and treated with metformin and other OHAs, for at least three visits were included. Analysis of BMI and the type of oral agent was performed. Individuals were categorized as ideal weight, overweight, or obese (BMI $<25,25-29.9$, and $>30 \mathrm{~kg} / \mathrm{m}^{2}$, respectively).

RESULTS: There were differences between the values of BMI at presentation, the third, the sixth and the ninth months, between the metformin-treated groups compared to other OHAs treated groups. Metformin was given to 48 patients and OHAs to other 57 patients. In the metformin group, mean BMI decreased significantly during the treatment time, from $29.93 \pm 5.7$ to $28.95 \pm 5.2(<0.001)$. The obese the patients, the lower their BMI levels at the end of the analysis period. The mean BMI dropped by $0.9 \pm 1.18$ in metformin group (from $29.93 \pm 5.7$ to $\left.24.83 \pm 3.6 \mathrm{~kg} / \mathrm{m}^{2} ; \mathrm{p}<0.001\right)$. It was found that the patients who had BMI higher than $30 \mathrm{~kg} / \mathrm{m}^{2}$ were significantly more likely to lose weight during the metformin therapy $(\mathrm{p}<0.05)$. However, the baseline change in body weight observed during metformin treatment correlated with the baseline metabolic control or its improvement during the analysis period.

CONCLUSION: Metformin use is associated with a significant decrease in body weight and BMI over long periods of time and it should remain a first choice drug for newly diagnosed T2DM patients, even more so for patients that are overweight or obese.

(C) Nepalese Association for Clinical Chemistry

\section{Introduction}

Diabetes Mellitus (DM) is a chronic metabolic disorder characterized by the presence of hyperglycemia due to either a deficiency in the production or secretion of insulin, diminished tissue response to the actions of insulin, or both $[1,2]$. Prevalence data indicate that diabetes has reached epidemic proportions worldwide, particularly in developed countries and emerging nations [3, 4]. The Nepal Diabetes Association reported that diabetes affects approximately $15 \%$ of people over 20 years and $19 \%$ of people over 40 years of age in urban areas of Nepal [5].

Although both type 1 and type 2 diabetes can potentially cause similar complications, the majority of diabetes related health care expenditures is spent on the treatment of complications in patients with T2DM [6]. Indeed, the vast majority of cases of Diabetes are T2DM [7].

T2DM has not just reached epidemic proportions worldwide. The number of affected individuals is increasing at a much faster rate than was originally predicted. Not surprisingly, the use of oral hypoglycemic agents used to treat this disease is also increasing rapidly.

Significant racial and ethnic disparities exist in the management of Diabetes $[8,9]$. The aim of this study was to evaluate the effect of Metformin use on the BMI in Nepalese Diabetic patients. Nepalese are known to have a relatively lower BMI compared to Caucasians, Hispanics and African Americans. Our primary objective was to see whether Metformin affected the BMI significantly in Nepalese diabetics.

T2DM is treated with diet and exercise, coupled with oral hypoglycemic medications, insulin sensitizers, medications that impede hepatic production of glucose and prescribed insulin.

\footnotetext{
'Department of General Practice and Emergency Medicine, Tribhuvan University Teaching Hospital; ${ }^{2}$ Department of Biochemistry, Institute of Medicine
}

Correspondence to: Aseem Bhattarai, Department of Biochemistry, Institute of Medicine, Kathmandu, Nepal. E-mail: dr.a.bhattarai@iom.edu.np 
However, hypoglycemia, gastrointestinal side effects, weight gain, and lack of optimal control of postprandial glucose are limitations that may present with the use of these T2DM treatments, preventing patients from reaching glycemic control. Metformin is a medication that can significantly lower glycated hemoglobin (HbA1c), body weight, and postprandial glucose excursions in humans and significantly improve $\beta$-cell function. It has biological effects that slow gastric emptying and decrease appetite [10-14].

Till date, three biguanides have been used widely in patients with T2DM: metformin, phenformin and buformin; but only metformin remains part of today's worldwide pharmacopoeia. While there are close similarities between these drugs the unique properties of metformin explain its long lasting appeal. Metformin is of smaller molecular weight, more chemically stable, freely soluble in water and does not undergo substantial metabolism in vivo. Metformin acts by countering insulin resistance, which is thought to occur in principally in liver and muscle. Metformin has been used in the treatment of patients with T2DM since 1957 in Europe and 1995 in the Unites States. It is now the most commonly prescribed oral hypoglycaemic agent worldwide $[13,14]$.

In contrast to most other anti-diabetic drugs, Metformin often leads to modest weight reduction or weight stabilization. Due to its effects in suppressing the hepatic production of endogenous glucose and in increasing insulin sensitivity in adipose tissue and skeletal muscle, the agent is used particularly in T2DM and metabolic syndrome, in which insulin resistance is especially pronounced [13-16].

Although several studies clearly advocate the use of metformin as a drug of choice in patients that are overweight, both in terms of weight reduction as well as glycemic control, quite a few studies have shown ambiguity and the need for a study depicting our population couldn't be overemphasized at this point.

Our study intended to see if the use of Metformin as a choice of drug for T2DM was associated with a significant weight reduction in Diabetic patients.

\section{Methods}

A prospective cross sectional and noninterventional analysis was done following 115 patients in the out-patient and in-patient settings between January to October 2010. Both male and female diabetic patients aged 18 and above, among which, a total of 48 patients on Metformin and another 67 patients on other OHAs were included in the study.

The information collected included age, sex, weight, height, Blood Sugar levels and BMI. The BMI was documented at zero, three, six and nine months after metformin and other OHA use.

\section{Results}

At presentation, $14 \%(n=16)$ of the total selected patients $(n=115)$ were in the normal weight category according to their BMI and a further $42 \%(n=48)$ and $44 \%(n=51)$ in the overweight and obese categories respectively.

Among the 48 patients using Metformin at the start of the study, $85 \% \quad(\mathrm{n}=41)$ were either overweight or obese. Incidentally, patients using other OHAs at the beginning of the study were mostly in the ideal weight category $(58 \%, n=39)$.

The mean values of BMI between the two groups of patients were significantly different to start with, and further analysis revealed the mean values of BMI at three, six and nine months to be significantly different yet $(\mathrm{P}<0.001)$, as shown in Table 1.

Table 1. Mean Values of BMI across groups at different intervals

\begin{tabular}{|c|c|c|c|}
\hline & $\begin{array}{l}\text { Patients on } \\
\text { Metformin }\end{array}$ & $\begin{array}{l}\text { Patients on } \\
\text { other OHAs }\end{array}$ & $\begin{array}{c}\text { p-values } \\
\text { (Pearson) }\end{array}$ \\
\hline BMI at & $29.93 \pm 5.7$ & $24.83 \pm 3.6$ & $<0.001$ \\
\hline Presentation & & & \\
\hline $\begin{array}{c}\text { BMI } \\
\text { (3 Months) }\end{array}$ & $29.73 \pm 5.5$ & $24.89 \pm 3.5$ & $<0.001$ \\
\hline $\begin{array}{c}\text { BMI } \\
\text { (6 Months) }\end{array}$ & $29.29 \pm 5.5$ & $24.82 \pm 3.5$ & $<0.001$ \\
\hline $\begin{array}{c}\text { BMI } \\
\text { (9 Months) }\end{array}$ & $28.95 \pm 5.2$ & $24.69 \pm 3.4$ & $<0.001$ \\
\hline
\end{tabular}

The mean reduction in BMI at the end of the third month was not significantly different between the two groups of patients, but at the end of the sixth month and the ninth months, the mean BMI reduction achieved was significantly different between the two groups of patients. $(0.63 \pm 0.93$ versus $0.00 \pm 0.7$ at the end of the third month, $\mathrm{p}<0.001$ and $0.97 \pm 1.18$ versus $0.13 \pm 0.75$ at the end of the ninth month, $\mathrm{p}<0.001)($ Table 2). 
Table 2. Mean BMI reduction at different time periods

\begin{tabular}{llcl}
\hline $\begin{array}{l}\text { BMI } \\
\text { difference at }\end{array}$ & $\begin{array}{l}\text { Patients on } \\
\text { Metformin }\end{array}$ & $\begin{array}{c}\text { Patients on } \\
\text { other OHAs }\end{array}$ & p-value \\
\hline $3^{\text {rd }}$ month & $0.19 \pm 1.07$ & $-0.06 \pm 0.31$ & $>0.05$ \\
$6^{\text {th }}$ month & $0.63 \pm 0.93$ & $0.00 \pm 0.7$ & $<0.001$ \\
$9^{\text {th }}$ month & $0.97 \pm 1.18$ & $0.13 \pm 0.75$ & $<0.001$ \\
\hline
\end{tabular}

Table 3. Mean BMI categorized at different Time Periods

\begin{tabular}{lcccc}
\hline $\begin{array}{c}\text { BMI } \\
\text { difference at }\end{array}$ & Ideal Weight & Overweight & Obese & p-values \\
\hline $3^{\text {rd }}$ month & $-0.048 \pm 0.78$ & $0.03 \pm 1.43$ & $0.43 \pm 0.67$ & $>0.05$ \\
$6^{\text {th }}$ month & $0.11 \pm 0.57$ & $0.60 \pm 1.23$ & $0.84 \pm 0.61$ & $>0.05$ \\
$9^{\text {th }}$ month & $0.23 \pm 0.39$ & $0.71 \pm 1.39$ & $1.46 \pm 0.86$ & $<0.05$ \\
\hline
\end{tabular}

Based on their BMI, patients (on metformin) were grouped, as mentioned before into three categories (ideal weight, overweight and obese), and a comparison of the mean reduction in BMI values between the categories as seen in follow ups in the third, sixth and ninth months was done which showed that at the end of three months, a greater reduction in BMI was achieved among patients in the obese category, although, statistically, the results were not significant (mean reduction achieved was $0.43, \mathrm{p}>0.05)$.

By the end of the sixth month, however, all patients showed a reduction in weight, with the patients in the obese category showing the greatest reduction and subsequently, BMI, but again, a statistical analysis did not reveal a strong association ( $\mathrm{p}$-value $>0.05)$.

At the end of the ninth month, however, on their third follow up, the reduction in BMI had increased in all categories, with patients in the overweight and obese categories showing a significant reduction (mean 0.71 and 1.46, respectively) in their BMI, with a strong statistical significance.

Further, an analysis of variance (ANOVA) was carried out to compare the mean reduction in BMI in patients and controls (in our case, patients on other OHAs), based on the different categories they fall under according to their BMI, this was cross tabulated against the different mean reduction levels in BMI achieved at the end of the third, sixth and the ninth months respectively, and the following results were obtained.

Thus, regardless of the time frame, the reduction of weight and subsequently, BMI, in patients on Metformin was always higher than that of the patients using other OHAs. At the end of the third month, however, the reduction achieved was not significantly different, but at the end of the sixth and ninth months, this difference was significant, as shown by Table 4 .

Table 4. Mean BMI reduction according to BMI category between groups

\begin{tabular}{|c|c|c|c|c|c|c|c|}
\hline \multirow[b]{2}{*}{$\begin{array}{c}\text { BMI difference } \\
\text { at }\end{array}$} & \multicolumn{2}{|c|}{ Ideal Weight } & \multicolumn{2}{|c|}{ Overweight } & \multicolumn{2}{|c|}{ Obese } & \multirow[b]{2}{*}{ p-values } \\
\hline & $\begin{array}{l}\text { Patients on } \\
\text { Metformin }\end{array}$ & $\begin{array}{l}\text { Patients on } \\
\text { other OHAs }\end{array}$ & $\begin{array}{l}\text { Patients on } \\
\text { Metformin }\end{array}$ & $\begin{array}{l}\text { Patients on } \\
\text { other OHAs }\end{array}$ & $\begin{array}{l}\text { Patients on } \\
\text { Metformin }\end{array}$ & $\begin{array}{c}\text { Patients on } \\
\text { other } \\
\text { OHAs }\end{array}$ & \\
\hline $3^{\text {rd }}$ month & $-0.04 \pm 0.78$ & $-0.12 \pm 0.32$ & $0.03 \pm 1.43$ & $-0.01 \pm 0.26$ & $0.43 \pm 0.67$ & $0.13 \pm 0.31$ & 0.025 \\
\hline $6^{\text {th }}$ month & $0.11 \pm 0.57$ & $-0.07 \pm 0.57$ & $0.60 \pm 1.23$ & $0.10 \pm 0.87$ & $0.84 \pm 0.61$ & $0.20 \pm 0.86$ & 0.001 \\
\hline $9^{\text {th }}$ month & $0.23 \pm 0.80$ & $-0.07 \pm 0.58$ & $0.71 \pm 1.39$ & $0.39 \pm 0.86$ & $1.46 \pm 0.86$ & $0.62 \pm 0.85$ & $<0.001$ \\
\hline
\end{tabular}

\section{Discussion}

For the mean duration of the study (nine months), Metformin was given to 48 patients and OHAs to 57 patients. In the metformin group, mean BMI decreased significantly during the treatment time, from $29.93 \pm 5.7$ to $28.95 \pm 5.2$ $(<0.001)$. Another notable figure was more obese the patient, the lower their BMI levels at the end of the analysis period. Mean BMI dropped by $0.97 \pm 1.18$ in Metformin group (from 29.93 \pm 5.7 to $24.83 \pm 3.6 ; \mathrm{p}<0.001$ ). It was found that the patients who had BMI higher than 30 were significantly more likely to lose weight during the metformin therapy $(\mathrm{p}<0.05)$. However, the baseline change in body weight observed during metformin treatment correlated with the baseline metabolic control or its improvement during the analysis period. A decrease in BMI values was achieved independently of metabolic control. The antihyperglycemic efficacy of metformin was therefore somewhat dissociated from its weightdecreasing effect as shown by our study.

Although several studies have shown the advantage of Metformin in diabetic patients, [17] the observation periods were relatively shorter. Clarke and Campbell reported that Metformin monotherapy $(\mathrm{n}=98)$ was equally effective as other OHA, on blood glucose control without 
HbA1c measurements, and that metformin was superior in the body weight control in T2DM according to a prospective study done for a year [18].

The efficacy of Metformin has been well proven in the last several years [19]. In our study, Metformin was effective in reducing BMI significantly with an average decrease by $0.97 \pm 1.18$ in $\mathrm{kg} / \mathrm{m}^{2}$ during the whole analyzed period. These results are in accordance with recent observations made by several authors, such as Hosokawa et al., [20] Garber et al., [21] and De Fronzo et al., [22] among others. However, the duration of these prospective studies did not exceed 6 months, which is considerably shorter than the period we analyzed. Given the outcome of our analysis we suggest that the Metformin is still efficacious, even though the maximum doses used in our patients did not exceed $2000 \mathrm{mg} /$ day. We cannot comment, however, on any doseresponse effect of Metformin, since the subjects included in our study did not change their dosage.

It is widely accepted that Metformin usually favors body weight loss [23]. Metformin treatment was associated in our patients with a small but statistically significant decrease in BMI, a mean of $0.97 \pm 1.18$. It is worth mentioning that the most obese patients, whose initial BMI was 30 or more, lost during the analyzed period a mean of $1.46 \pm 0.86 \mathrm{~kg} / \mathrm{m}^{2}$. As the analyzed group consisted of ideal weight, overweight and obese subjects, we were able to reveal a significant positive association between the initial BMI and the subsequent decrease in BMI, i.e. the more patients weighed, the more weight they were likely to lose. This association may be explained by the fact that metformin induces a decrease in BMI in a proportional manner, usually allowing for $2-5 \%$ decrease [24].

We believe that the dissociation between metformin's impact on glycemic control and decrease in BMI requires further prospective studies, involving more homogenous groups of patients. It has also been established that metformin use is better than other OHAs in Nepalese T2DM [5]. The results of the study suggest that metformin be the drug of choice in treatment of T2DM whenever body mass is concerned, even more so in terms of the Nepalese population.

\section{Conclusion}

It can be concluded from the study that metformin is associated with a significant decrease in body weight and BMI over long periods of time and it should remain a first choice drug for newly diagnosed T2DM patients, even more so for patients that are overweight or obese.
1. Alberti KG, Zimmet PZ. Definition, diagnosis and classification of diabetes mellitus and its complications. Part 1: diagnosis and classification of diabetes mellitus provisional report of a WHO consultation. Diabet Med 1998; 15(7):539-553.

2. Report of the Expert Committee on the Diagnosis and Classification of Diabetes Mellitus. Diabetes Care 1997; 20(7):1183-1197.

3. King H, Aubert RE, Herman WH. Global burden of diabetes 19952025: prevalence, numerical estimates and projections. Diabetes Care 1998; 21:1414-31.

4. Amos AF, McCarty DJ, Zimmet P. The rising global burden of diabetes and its complications: estimates and projections to the year 2010. Diabet Med 1997; 14 Suppl 5:S1-85.

5. Bhattarai MD, Singh DL. Learning the lessons - preventing type 2 diabetes in Nepal. Diabetes Voice 2007;52( 2): 9-10.

\section{References}

6. Chehade JM, Mooradian AD. A rational approach to drug therapy of type 2 diabetes mellitus. Drugs 2000; 60(1):95-113.

7. Clark CM, Jr., Perry RC. Type 2 diabetes and macrovascular disease: epidemiology and etiology. Am Heart J 1999; $138(5$ Pt 1):S330S333.

8. Yajnik CS, LUbree HG, Rege SS et al. Adiposity and hyperinsulinemia in Indians are present at birth. J ClinEndocrinolMetab 2002;87:5575-5580.

9. Wells JCK. Commentary: why are South Asians susceptible to central obesity? - the El-Nino hypothesis. Int J Epidemiol 2007;36:220-225

10. Turner RC, Cull CA, Frighi V, Holman RR. Glycemic control with diet, sulfonylurea, metformin, or insulin in patients with type 2 diabetes mellitus: progressive requirement for multiple therapies (UKPDS 49). UK Prospective
Diabetes Study (UKPDS) Group. JAMA 1999; 281(21):2005-2012.

11. United Kingdom Prospective Diabetes Study 24: a 6-year, randomized, controlled trial comparing sulfonylurea, insulin, and metformin therapy in patients with newly diagnosed type 2 diabetes that could not be controlled with diet therapy. United Kingdom Prospective Diabetes Study Group. Ann Intern Med 1998; 128(3):165175.

12. Davis SN. Insulin, Oral Hypoglycemic Agents, and the Pharmacology of the Endocrine Pancreas. Eleventh Edition ed. 2006.

13. Bolen S, Feldman L, Vassy J et al. Systematic review: comparative effectiveness and safety of oral medications for type 2 diabetes mellitus. Ann Intern Med 2007; 147(6):386-399.

14. Effect of intensive blood-glucose control with metformin on complications in overweight patients 
with type 2 diabetes (UKPDS 34). UK Prospective Diabetes Study (UKPDS) Group. Lancet 1998; 352(9131):854-865.

15. Grant RW, Wexler DJ, Watson AJ et al. How doctors choose medications to treat type 2 diabetes: a national survey of specialists and academic generalists. Diabetes Care 2007; 30(6):1448-1453.

16. Effect of intensive blood-glucose control with metformin on complications in overweight patients with type 2 diabetes (UKPDS 34). UK Prospective Diabetes Study (UKPDS) Group. Lancet 1998; 352(9131):854-865.

17. United Kingdom Prospective Diabetes Study Group. United Kingdom Prospective Diabetes Study 24: a 6-year, randomized, controlled trial comparing sulfonylurea, insulin, and metformin therapy in patients with newly diagnosed type 2 diabetes that could not be controlled with diet therapy. Ann Intern Med. 1998;128:165175.

18. Clarke BF, Campbell IW. Comparison of metformin and chlorpropamide in non-obese, maturity-onset diabetics uncontrolled by diet. $\mathrm{Br}$ Med J. 1977;2(6102):1576-1578.

19. Kaku K, Tajima N, Kawamori K. Melbin Observation Research (MORE) study of metformin therapy in patients with type 2 diabetes mellitus. J Japan Diab Soc. 2006;49:325-331.

20. Hosokawa K, Meguro S, Funae O. et al. Clinical effects of metformin with nonobese type 2 diabetes. J Japan Diab Soc. 2009;52:1-6.

21. Garber AJ, Duncan TG, Goodman AM, Mills DJ, Rohlf JL. Efficacy of metformin in type 2 diabetes: results of a double-blind, placebo- controlled, dose-response trial. Am J Med. 1997;103:491-497.

22. Defronzo RA. Banting Lecture. From the triumvirate to the ominous octet: a new paradigm for the treatment of type 2 diabetes mellitus. Diabetes. 2009;58:773-795.

23. Donnelly LA, Doney AS, Hattersley AT, Morris AD, Pearson ER. The effect of obesity on glycaemic response to metformin or sulphonylureas in Type 2 diabetes. Diabet Med. 2006;23:128-133.

24. Kahn SE, Haffner SM, Heise MA. et al. Glycemic durability of rosiglitazone, metformin, or glyburide monotherapy. N Engl J Med. 2006;355:2427-2443.

25. Ong CR, Molyneaux LM, Constantino MI, Twigg SM, Yue DK. Long-term efficacy of metformin therapy in nonobese individuals with type 2 diabetes. Diabetes Care. 2006;29:2361-2364. 